\title{
Os Filhos de Guilherme Tell: Breve ensaio sobre as gerações artísticas cubanas ${ }^{1}$
}

\author{
Los hijos de Guillermo Tell: \\ Breve ensayo sobre las generaciones artísticas cubanas
}

\section{The children of William Tell: A brief essay on Cuban art generations}

\author{
Concepción R. Pedrosa Morgado*
}

Palavras chave:

Gerações Culturais Cubanas

Gerações Artísticas

Cubanas

Generación de los Ochenta Cubana

Geração dos Oitenta

Cubana

Artes Plásticas em Cuba

Filhos de Guilherme Tell
Resumo:

Este ensaio é um breve resumo de parte da dissertação do Mestrado em Ciência da Arte, defendida na Universidade Federal Fluminense em 2001. O trabalho faz uma introdução ao estudo das gerações artísticas cubanas, focalizando sua atenção na chamada "Generación de los Ochenta", que marcou presença no panorama da arte contemporânea nas duas últimas décadas do século XX e se atreveu a questionar os dogmas de um estado projetado até esse momento ante a opinião nacional como perfeito, sem renunciar à identidade com os princípios políticos e sociais defendidos por esse mesmo estado; uma geração que se propôs abrir portas e derrubar muros, e só conseguiu abrir janelas - amplas o suficiente como para focalizar a atenção do povo cubano e do resto do mundo, na ocorrência de um fenômeno artístico que focalizou entre suas principais propostas a discussão aberta de problemas extra-artísticos vinculados à questões sociais e políticas, tendo especial cuidado de não cair nos extremos panfletários ou propagandísticos das obras - entendidos como banalização e corrupção - de suas idéias. Esta Geração teve o perfil do momento histórico que lhe deu origem e sustento, e que ao mesmo tempo, conseguiu conquistar com sua própria voz, a atenção sobre uma outra face da política cubana, partindo dos mitos sobre a formação do "homem novo", e trouxe à tona, desde novos pontos de vista, a discussão aberta sobre os direitos das novas gerações, nascidas sob o significante da Revolução Cubana.

\footnotetext{
* Mestre em Ciência da Arte, UFF, 2001; Lic em História da Arte, Universidad de La Habana, Cuba, 1982. Crítica de Artes; Curadora; Professora na Universidade Salgado de Oliveira. Coordena a Pós-Graduação em História da Arte Moderna e Contemporânea nessa Faculdade.
} 
Resumen:

Este ensayo es un breve resumen de parte de la disertación de la Maestría en Ciencia del Arte, defendida en la Universidad Federal Fluminense en 2001. El trabajo hace una introducción al estudio de las generaciones artísticas cubanas, focalizando su atención en la llamada "Generación de los Ochenta", que marcó con su presencia el panorama del arte contemporáneo de las dos últimas décadas del siglo XX y se atrevió a cuestionar los dogmas de un estado proyectado como perfecto hasta ese momento ante la opinión nacional, sin renunciar a la identidad con los principios políticos y sociales defendidos por ese propio estado. De este proceso resultó una generación que se propuso abrir puertas y derribar murallas, y solo consiguió abrir ventanas lo suficientemente amplias como para focalizar la atención del pueblo cubano - y del resto del mundo - en la existencia de un fenómeno artístico que focalizó entre sus principales propuestas la discusión abierta de problemas extra-artísticos vinculados a cuestiones sociales y políticas, poniendo especial énfasis en el cuidado de no caer en extremos panfletarios o propagandísticos de las obras - entendidas como banalización o corrupción - de sus ideas. Esta Generación tuvo el perfil del momento histórico que le dio origen y sustento, y que al mismo tiempo, consiguió conquistar con su propia voz, la atención sobre otra faceta de la política cubana, partiendo de los mitos sobre la formación del "hombre nuevo", y colocó en primer plano, desde nuevos puntos de vista, la discusión abierta sobre los derechos de las nuevas generaciones, nacidas bajo el significante de la Revolución Cubana.

\section{Palabras clave:}

Generaciones Culturales Cubanas

Generaciones Artísticas Cubanas

Generación de los Ochenta Cubana

Artes Plásticas en Cuba

Hijos de Guillermo Tell

\section{Key words:}

\section{Cuban Cultural Generations}

Cuban Art Generations

Generation of the Eighties in Cuba

Arts in Cuba

Childrens of William Tell

\section{Abstract:}

IThis essay is a brief summary of the dissertation of the Master in Science of Art, de-fended at the Fluminense Federal University in 2001. The paper gives an introduction to the study of Cuban artistic generations to focus its attention on the "Generation of the Eighties", a group which influenced the development of contemporary art of Cuba in the last two decades of the 20th century. This investigation comprehends a wide view of the Cuban cultural evolution through its recent history. There is a novel approach to the inner works of a generation that had the audacity to defy state's dogmas, accepted as normal by public opinion, while maintaining its identity with the social and political doctrines enforced by the state. Out of this process came a group of artists proposing to unlock doors and tear down walls, and could open windows wide enough to be recognized by Cubans and worldwide as a new artistic phenomenon. These artists included among their goals an unrestricted discussion on extra-artistic problems related with social and political questions, but avoided the banality and the propagandistic diffusion of their ideas. It was a Generation, shaped by a historical moment, that could define their objectives and ideals, and was able to conquer a social and cultural position. It was a Generation that focused on another side of Cuban politics: taking as the starting point the myth of the "new man", these artists brought to a relevant place, and from a new point of view, an open debate about the rights of new generations born within Cuban Revolution. 


\section{Os Filhos de Guilherme Tell: Breve ensaio sobre as Gerações artísticas cubanas}

\section{AS GERAÇÕES CULTURAIS CUBANAS COMO MARCAS DE IDENTIDADE}

Na análise do fenômeno geracional na cultura cubana, observamos como a regularidade e persistência na identificação e proclamação de filiação intelectual de grupos com um ideário político, artístico, social ou cultural comum, ao longo do percurso da história do país, transcende os marcos anedóticos e circunstanciais para se afirmar como um dos fatos característicos que marcaram a identidade da Ilha.

O conceito de geração, em uma leitura sócio cultural ampla, inclui dentro de seus marcos a todas aquelas pessoas com referentes comuns culturais, políticos, ideológicos e/ou sociais. É um conceito que transcende os limites de fronteiras territoriais, e muitas vezes, transcende os próprios limites da promoção geracional, contando dentro de suas fileiras aquelas pessoas que com seu pensamento ou sua ação, ou ambas, ultrapassam as fronteiras epocais, iniciando a militância em idéias, estilos, correntes ou movimento que só chegam a vingar muito tempo depois dos pioneiros que as geraram.

Segundo as definições tradicionais, o termo Geração nomeia a função pela qual os seres humanos se reproduzem. Também é a série de organismos semeIhantes que se originam uns dos outros. É a linhagem, ascendência, genealogia; o espaço de tempo que separa cada grau de filiação. Cada século compreende cerca de três gerações. É o conjunto de pessoas que vivem na mesma época e também o conjunto de pessoas que têm mais ou menos a mesma idade. À exceção das teorias medievais da Geração espontânea, que aceitava a idéia da formação espontânea de organismos vivos a partir de matéria organizada, ou de substâncias em decomposição; o conceito de geração é portador natural da idéia de evolucionismo.

Segundo o já questionado evolucionismo, no plano cultural ou artístico, para que um organismo ou sistema qualquer seja gerado, são imprescindíveis a existência de condições específicas que permitem a aparição de um outro conjunto de elementos sistêmicos contendores, por definição, de qualidades diferenciadas de aquelas outras que a geraram.

O século XX em Cuba esteve pautado pela marca das sucessivas gerações políticas e artísticas, que reivindicaram sua existência e ação no meio sociocultural da Ilha. O fenômeno é tão insistentemente repetido que muitos cientistas, historiadores e estudiosos em geral da cultura cubana fizeram múltiplas abordagens do tema, seja de maneira geral - o fato em sua totalidade - seja na aproximação a gerações específicas, em sua relação com o período focalizado.

Entre eles podemos citar os estudos históricos feitos por Emilio Roig de Leuchsenring, as abordagens antropológicas e sociais feitas por Dom Fernando Ortiz e Ramiro Guerra, as análises das gerações literárias feitas por José Antonio Portuondo e por Ambrósio Fornet e as abordagens abrangentes nos estudos de Juan Marinello, Iván de la Nuez, Rafael Rojas, Gerardo Mosquera, Osvaldo Sánchez Crespo, Rufo Caballero, Jesús Diaz e Antonio Benítez Rojo.

Os pontos de vista de José Antonio Portuondo ${ }^{2}$, mesmo focalizados nas gerações literárias da Ilha, pareceram-nos pertinentes para a abordagem do nosso estudo particular. Fiel à sua filiação mar- 
xista, o crítico fez a citação das idéias de Karl Marx e Frederico Engels contidas no tratado sobre A Ideologia Alemã, datado entre 1845 e 1846 . Nelas se reafirma que:

"A história não é outra coisa senão a sucessão das diversas gerações. Cada uma delas explora os materiais, os capitais, as forças produtivas que lhe foram transmitidas por todas as precedentes. A nova geração continua as atividades das anteriores, mas não o faz sob as mesmas circunstâncias. Como a nova geração, além de prosseguir as atividades das anteriores, empreende outras completamente novas, modificando com isto em um todo, as circunstâncias que lhe foram deixadas como herança."..."A nova geração modifica sem dúvida o patrimônio legado pela geração anterior. Mas isso não tira que aquele influa poderosamente nela, prescrevendo o caminho por onde haverá de se desenvolver e conferindo um caráter especial. Portanto, as circunstâncias fazem aos homens não menos que os homens às circunstâncias"3.

Do que se infere que o homem sujeito da história e portador dos conhecimentos, conhecedor do espírito de uma época, não necessariamente irá continuar o legado das anteriores. Antes pelo contrário, está implícita uma oposição à totalidade, ou à parte dos elementos que provocaram seu surgimento diferenciado.

Portuondo delimita algumas características essenciais à tomar em conta no estudo das gerações, sejam quais foram sua tendência ou classificação.

Em primeiro lugar, assinala o nasci$\underline{\text { mento }}$, a data de publicação e a influência dos autores em cada geração e destaca o que chama "um conceito luminoso de W. Pinder" "o sincronismo vital dos que não são contemporâneos"4. Incluída dentro desta característica se encontra a dura- ção temporal das gerações, isto é, o tempo de vida dos participantes, o que também influenciará na formação de derivados ou promoções da geração em si.

Em segundo lugar, Portuondo destaca aos Elementos Formativos da Geração, isto é, a homogeneidade da educação ou da formação dentro do fenômeno geracional. A qualidade da geração inclui o empenho de modelar à geração seguinte à sua imagem e semelhança. Portuondo destaca como as relações pessoais, ou seja, a interação relativa entre os membros da geração viabilizada no meio literário através de revistas, tertúlias, academias, congressos, eventos, e qualquer acontecimento que propicie ou facilite $o$ encontro e troca de idéias entre os mesmos, está em relação direta com os manifestos e pronunciamentos dos grupos, as tendências e as escolas.

Em terceiro lugar temos o que ele cataloga como o Acontecimento ou Experiência Geracional, definido como um fato histórico de tal importância que, recaindo sobre um determinado grupo humano, opera como elemento de coesão e contribui a criar um estado de consciência coletiva que se faz extensiva à geração que de ele participa ${ }^{5}$.

Em quarto lugar coloca o que ele chama de "Caudillaje" e que preferimos traduzir como Liderança, aos efeitos de nosso estudo. Segundo Portuondo, cada geração e cada classe criam um personagem ideal que encarna e resume as apetências contemporâneas do grupo ${ }^{6}$.

Em quinto lugar vêm o que Portuondo chamou de Linguagem Geracional. Ele explica a tendência repetida em cada geração de criar sua própria linguagem, que vai além do seu simples destino de comunicação, no tocante à sua missão como instrumento de expressão. 
"Neste ponto as mesmas palavras diferem de uma à outra geração e algumas se gastam como as moedas, no tráfego cotidiano e outras renascem carregadas de inédito sentido. Nada revela tão agudamente o instante de transição entre grandes épocas históricas como a preocupação pela lingua-gem, e este renascimento que presenciamos em estudos lingüísticos, menos preocupados dos acidentes ortográficos e fonéticos das línguas que de seus valores expressivos e semânticos, nos está a dizer que o homem prepara seu instrumento melhor para viver em novas circunstâncias históricas"?.

Por último, Portuondo assinala a aniquilação da geração anterior como signo da existência e identificação de uma geração determinada. Neste ponto, destaca o processo dialético das gerações, em que a contradição com os postulados básicos da anterior serve de estímulo para o surgimento e definição da próxima. Cita o teórico Max Scheler ${ }^{8}$ referente à forte luta que há de enfrentar cada jovem geração, com o ressentimento da velha. Ressentimento que se faz patente na oposição sistemática das academias em que as forças reacionárias costumam se entrincheirar, frente às inovações "vanguardistas" de todas as idades.

A análise de Portuondo - referida ao estudo das gerações literárias em Cuba serviu de base à nossa aproximação ao comportamento das gerações artísticas, que invocam um fenômeno que é, de fato, mais abrangente. Através de nossa análise conseguimos comprovar como a totalidade das características enunciadas acima, estão presentes no comportamento específico do tema central do nosso estudo, a "Generación de los Ochenta" cubana.

No entanto, em um olhar abrangente sobre o comportamento geral do fenômeno das gerações em Cuba, dois aspectos chamaram à nossa atenção $\mathrm{Em}$ primeiro lugar, focali-zamos o fato concreto da persistência de sucessivas gerações em Cuba, identificadas a partir de meados do século XIX. A estirpe e filiação das mesmas ultrapassa as fronteiras da cultura, e abrange os interesses políticos dos contemporâneos que as integraram.

Assim podemos reconhecer as gerações pertencentes à primeira (1868-1878) e à segunda (1895-1900) guerras independentistas. Mesmo estando pautadas por interesses similares, podemos apontar algumas diferenças sutis. Se a primeira geração teve contornos gerais mais indefinidos, à causa da sucessão dos lideres da mesma e a oscilação entre as diferentes classes sociais que se foram somando paulatinamente aos acontecimentos; a segunda - sob a liderança dos grupos revolucionários atuantes no exílio, e com a regência extraordinária de José Martí - definiu mais radicalmente a intenção irredutível da liberdade nacional e conseqüentemente, a atuação e dinâmica interna entre seus componentes.

A geração dos '20 - que inclui no terreno das artes, a identificada como Primeira Geração Vanguardista, ou a Geração da Revista de Avance - teve uma orientação mais definidamente radical na área da política, com o enfrentamento à corrupção interna e a submissão aos governos norte-americanos, que a olhos vistos contrariavam os princípios independentistas sustentados pela geração anterior e que no plano cultural teve a intenção de discutir os elementos componentes da cultura nacional, junto à necessidade de imprimir uma dimensão de contemporaneidade e de vínculo internacional às artes da Ilha. Sua diferença estética com as gerações anteriores esteve marcada pela escolha das linguagens visuais $e$ literárias pertencentes à vanguarda, em 
sintonia com o espírito geral da época. A geração dos ' 40 - pautada por um intimismo e recolhimento maiores - acusava o fracasso dos levantamentos populares e da greve geral que marcou a chamada "Revolução do '33". No plano cultural foi identificada como a "Geração de Orígenes", tomando o caráter sofisticado da revista que agrupou o melhor da inteligência cultural da época.

A geração dos '50 esteve pautada pela volta aos interesses cidadãos, pela luta por uma verdadeira independência política. Ela incluiu aos jovens que se reuniram em torno às atividades da "Sociedade Cultural do Nosso Tempo", que encaminhava as propostas culturais do Partido Socialista Popular - mascarada nomeação do Partido Comunista Cubano - dirigido por uma equipe dos mais brilhantes e esclarecidos intelectuais do momento - entre eles estava Juan Marinello, como sobrevivente das inquietações da Geração dos '20.

Integrantes da geração dos ' 50 , foram por direito próprio os membros da chamada "Geração do Moncada", o grupo que começou o processo de conscientização cidadã com o assalto ao quartel Moncada na região oriental do país, liderados pelos jovens Fidel Castro Ruz e Abel Santamaria Cuadrado, que mais tarde continuariam desde o exílio a organização da luta de guerrilhas - continuada logo em solo cubano, na área da Serra Maestra - e que levariam posteriormente à invasão do território insular com o apoio da quase totalidade da população, e à toma do poder pelos populares "barbudos" na histórica entrada em Havana em 2 de janeiro de 1959.

Depois do triunfo revolucionário, a existência da Geração dos sessenta - que não obedeceu a uma padronização de idades entre seus componentes e sim à identificação de cada um deles com os postulados éticos e estéticos propostos pelo novo estado; seguidas pela chamada "Generación de la Esperanza Cierta" e posteriormente pela polêmica "Generación de los Ochenta" - cada uma delas, analisadas com certo grau de aproximação no percurso do presente estudo ${ }^{9}$ - ainda pautadas pela especulação da existência ou não de uma Geração dos Noventa, nos leva ao segundo ponto de interesse, focalizado no curto intervalo existente entre uma geração e outra. Em torno a este aspecto, Portuondo atribuía um intervalo de trinta anos à vigência temporária das gerações.

Nos casos anteriormente assinalados, é óbvio que a vibração temporal de uma geração é extinta pelo surgimento da seguinte em espaços de tempo muito menores - às vezes no curto espaço de uma década $e$ às vezes chegam a assinalar-se períodos pouco maiores que um lustro- o que nos leva a concluir que o cúmulo de eventos acontecidos em um período de tempo breve leva à criação acelerada de uma experiência geracional que inclui tanto aos elementos pertencentes à outras gerações, que evoluem em suas posições assumindo destaque - e até liderança - nos novos períodos, como a incorporação de novos elementos, cuja visão em torno à situação geral e cujo estado de opinião, foi formado ao calor destes novos acontecimentos.

A linguagem geracional entendida como um tipo de vocabulário particular que inclui o repertório de elementos que formam a visualidade da época, traçados por uma estética determinada, além dos elementos particulares pertencentes à língua ou à gíria comunicacional - que se constitui em uma espécie de código particular para ser entendido pelos sujeitos que se identificam com essa específica geração - evoluiu velozmente nas três últimas gerações acontecidas no século $X X$ na Ilha: as correspondentes às décadas dos 
sessenta, dos setenta e dos oitenta, ao ponto que as atitudes explícitas de rejeição da geração dos oitenta à anterior geração dos setenta, foram muito mais radicais e ferinas, que a suave superposição entre os postulados das gerações precedentes.

\section{O EXÍLIO DOS NÁUFRAGOS. A SÍNDROME DE URANO. ÊXODO E DISPERSÃO.}

A modo de esclarecimento, é necessário lembrar que o presente ensaio se apóia na dissertação ${ }^{10}$ sobre a geração artística cubana conhecida como "Generación de los Ochenta", onde cada tema foi extensamente desenvolvido. Devido a esta contingência particular, a conclusão deste trabalho foi concretizada a partir da obrigatoriedade de fechar o sistema de estudos desenvolvidos em torno às particularidades da existência da "Generación de los Ochenta" cubana, ela importa à somatória das observações que viemos fazendo, de maneira paulatina ao longo de todo nosso percurso analítico. Porém a escala pessoal, não consideramos as presentes reflexões como conclusivas da análise de um período criativo tão polivalente e diverso como foi a antes mencionada Geração, assim como também não consideramos que a energia criativa despertada pela mesma tenha sido definitivamente esquecida ou enterrada. Em função de conseguirmos uma maior objetividade, decidimos ir desenvolvendo a corrente de pequenas conclusões parciais para chegarmos à conclusão da percepção do fenômeno em sua totalidade.

No percurso da nossa análise estudamos a maneira em que a imagem poéti-

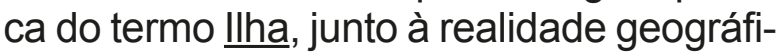
ca e histórica dos ilhéus, convergiram felizmente nos diversos períodos da produção plástica cubana como singularidade. No processo de aproximação ao fenômeno particular da "Generación de los Ochenta", comprovamos em primeiro lugar, a existência de uma cultura cubana definida no contexto particular do país, assim como as circunstâncias que determinaram o seu surgimento e posterior consolidação.

A llha de Cuba não contou com uma população autóctone, seus primeiros habitantes chegaram de terras continentais próximas, e já no território, se assentaram e continuaram a linha evolutiva de suas culturas originárias.

Posteriormente, com a chegada dos espanhóis em 1492, sua possessão foi avaliada pelo fato de constituir uma ponte intermediária entre o chamado "Novo Mundo" e as metrópoles européias. Isto influenciou no fato de que sua condição insular estivera sempre destacada nas transações econômicas, nas reivindicações sociais e nas manifestações artísticas - especialmente na literatura, na poesia e nas artes visuais e dramáticas.

As guerras independentistas de meados e finais do século XIX e a entrada no século $X X$ estreando sua condição de República foram refletidas na produção plástica nacional, que reivindicou seu perfil nacionalista desde finais da década dos '20, e continuaram seu curso, mais ou menos alinhadas em sintonia com as correntes de vanguarda internacionais até princípios da década dos sessenta do passado século.

O triunfo revolucionário de 1959 reafirmou a vocação de soberania preconizada por José Martí, quem foi assumido como Mentor espiritual dos rebeldes na llha, na chamada "Generación del Moncada"12. Desde muito cedo, Fidel Castro como Comandante em Chefe da Revolução, definiu as posições da novíssima República de Cuba, no sentido de criar e fortalecer um elo cultural com o Continente Latino-Americano e com os países do Terceiro Mundo. 
A partir de 1959, Cuba tem vindo à tona no cenário mundial em várias oportunidades, à causa das suas posições políticas radicais e do seu constante enfrentamento com os Estados Unidos em um jogo estratégico de tensões econômicas e políticas que tem a Fidel Castro como pivô essencial.

Conseqüência desta situação foi a chamada Crise de Outubro, desatada pela presença de mísseis soviéticos situados em pontos estratégicos da llha , que estremeceu à Latino-América na década dos sessenta, com a possibilidade de um conflito atômico na região do Caribe - o que teria seqüelas desastrosas na ecologia dessa parte do planeta, além da repercussão política e social - a frustrada Invasão de mercenários pela Bahia dos Porcos, como resultado da cada vez maior influência dos chamados "cubanos de Miami" dentro do Congresso norte-americano; o conflito subterrâneo entre ambos estados, livrado nos campos de batalha de Angola, Etiópia, Nicarágua e tantos outros países que tiveram "assistência especializada" tanto dos Estados Unidos, como do governo cubano; as constantes evasões de cubanos fugindo do regime socialista em direção à uma miragem paradisíaca, e as freqüentes infiltrações de agentes em ambos territórios.

A liderança do governo cubano como foco revolucionário, e ponto constante de desestabilização a só noventa milhas dos Estados Unidos, esclarece, mas não justifica, atitudes desumanas como o embargo econômico imposto e sustentado pelos diversos governantes norte-americanos, desde há mais de quarenta anos, até a atualidade. Exemplos de humanismo e solidariedade foram ditados em diversas ocasiões pelo governo e pelo povo cubano, com as doações de sangue e a ajuda médica à países latino-americanos vítimas de desastres ecológicos, ou estremecidos por conflitos bélicos.
No território da produção artística, os pressupostos enunciados nas $\underline{\text { Palavras }}$ aos Intelectuais, de 1961, traçaram a linha sutil das liberdades de criação dentro do sistema revolucionário. As transformações políticas, econômicas e sociais acontecidas durante o processo de construção da nova sociedade, influenciaram no clima cultural em geral e no clima artístico em particular dos anos '60 e ' 70 , correspondentes às duas primeiras décadas do triunfo revolucionário. A arte produzida em cada uma destas décadas teve características próprias, inerentes à época em que foi gerada. Uma arte de viés épico que caracterizou a década dos sessenta e uma arte triunfalista, discursiva e propagandística, que marcou a década dos setenta.

Há alguns anos, tive a honra de participar como palestrante de um importante evento que debatia a cultura e a violência ${ }^{13}$. Nele conheci alguns pontos de vista sobre o fenômeno, que desencadearam com posterioridade a série de reflexões que agora coloco em preto sobre branco. Sem cair na pretensão de fazer especulações ou contribuições no amplo campo das teorias sobre o avanço e o papel da violência na cultura contemporânea, gostaria inserir algumas considerações sobre a importância da interrelação entre o silêncio privado e o silêncio público. Segundo as teorias desenvolvidas por um grupo de pesquisadores do fenômeno da violência, existem os silêncios necessários, que são definidos como aqueles espaços de percepção que permitem a melhor captação da mensagem artística, cultural e midiática.

Se o silêncio privado pode ser identificado com qualidades contraditórias como silêncio criador, com o silêncio modesto, com o silêncio da incapacidade e também com o silêncio da auto-censura; podemos considerar o silêncio público como uma soma de si-lêncios privados. Isto nos leva a interpretar os silêncios do 
coletivo, os silêncios sobre de-terminadas falhas e falências de um sistema, a ausência de comentários críticos, pode ser interpretada opcionalmente já seja como aceitação dessa realidade, como sintoma de felicidade; já seja como conseqüência da repressão de qualquer expressão negativa, exercida desde instâncias superiores; já seja como uma somatória de auto-censuras. Se qualquer repressão já é sintomática de violência, a última das alternativas enunciadas pode resultar em uma ação muito mais violenta, enquanto coletiva.

Se qualquer manifestação da violência é capaz de deixar marcas inesquecíveis, a marca do silêncio da auto-censura deve ser mais profunda ainda, já que cada indivíduo participa com seu silêncio - por tanto, com sua cumplicidade - do ritual da repressão coletiva. A violência maior que se pode infringir a um coletivo social é a destruição da sua memória coletiva através da imposição de uma reconstrução paranóica da história imediata - que obriga a cada indivíduo a ir apagando na reconstrução interna dos fatos seus silêncios ominosos, sujos, culpáveis.

As Mães da Praça de Maio na Argentina são um exemplo da persistência da memória de uma porção da história paralela que é contada por protagonistas que permanecem alienados no seu drama pessoal, e cuja insistência na denúncia dos fatos que constituem sua triste cotidianidade, impede que suas parcelas de história sejam apagadas, devoradas pela conivência da história "oficial" digna e convenientemente contada.

Podemos definir a realidade da existência da violência como sedução ou da sedução pela violência no contexto social, isto é, a maneira em que a vida contemporânea subverte os termos de equilibro e de calma, quebrando-os por sistemáticos períodos de violência social. O algorit- mo da civilização vai encurtando seus períodos e, conseqüentemente, subvertendo suas etapas, trocando de lugar a perigosa tendência do estado habitual, controlado, da violência dentro da sociedade, quebrada por períodos de equilíbrio que funcionam como redistribuidores de tensões.

A arte da "Generación de los Ochenta" funcionou como válvula de escape das ten-sões acumuladas durante as primeiras décadas de construção e instrumentação do Estado revolucionário cubano. A violência da auto-censura imposta pelo sucessão dos acontecimentos e por falsos sentimentos de solidariedade e cumplicidade com o status estabelecido, enxergou uma via de expressão, na inquietação criativa desses jovens artistas. O espírito da primeira destas conclusões pode ser resumido nas palavras escritas em uma das peças ${ }^{14}$ expostas no acontecimento-exposição El Objeto Esculturado de 1990, que mostrava uma instalação que com uma lâmpada comum, com o filamento interior solto:

"Não foi desligado do suporte (continua
alimentando-se de eletricidade). No foi
agredido fisicamente (é evidente que
não se procedeu com violência). Não
esperaram que se fundisse, não desa-
pareceu fisicamente... não opõe resis-
tência, e parece estar a vontade...mas
não projetará luz jamais".

A segunda conclusão focaliza como a "Generación de los Ochenta" sintetizou de maneira orgânica a concretização do projeto educacional do Estado Cubano, enunciado nos documentos programáticos promulgados durante 0 período Revolucionário e posteriormente, reafirmados no Período que identificamos como Pós-Revolucionário - caracterizado pela institucionalização, sedimentação e burocratização das estruturas políticas, sociais, culturais e econômicas do 


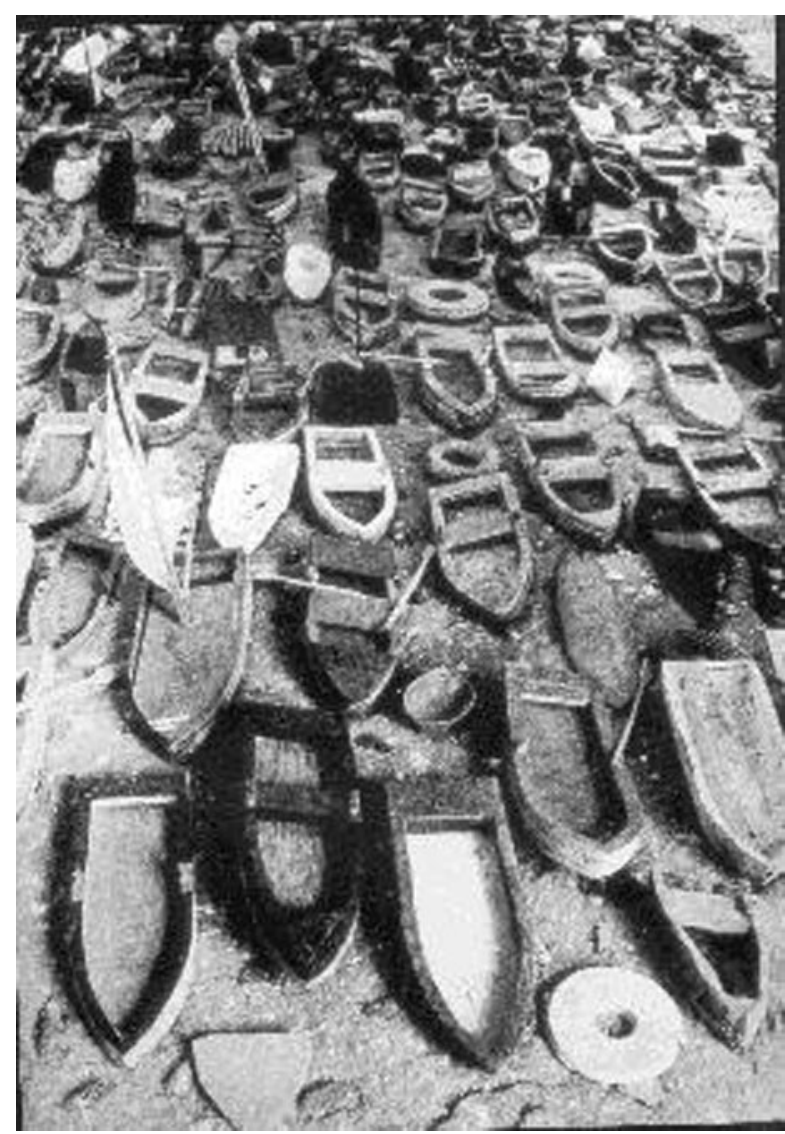

Figura 1 - Kcho. Regata. Instalacão, 1994

país. Os artistas da "Generación de los Ochenta" - que em sua imensa maioria esteve formada por jovens procedentes de famílias de extração humilde - tiveram uma educação equiparável à dos mais altos níveis dos países do chamado "Primeiro Mundo" e uma vez formados como profissionais passaram a integrar, com a sofisticação dos seus projetos, as filas da forte intelectualidade de vanguarda do país, ao tempo que conseguiram a integração com setores populares, e a qualificação das comunidades onde desenvolveram seus projetos.

Mas não foi o legado revolucionário o único recolhido por estes jovens ilhéus dos anos Oitenta, eles também conseguiram projetar em suas criações a multiplicidade da identidade cultural cubana. A "Generación de los Ochenta" recolheu as inquietações da personalidade do cubano como singularidade; seu posicionamento herdado da ancestral contraposição colônia-metrôpole, ilha-continente, influenciou na insistência de uma definição não submissa a manipulações institucionais nacionais ou internacionais. Foi uma geração artística que ganhou por mérito próprio seu lugar no panorama das artes da após-a-pós-modernidade.

A existência da Geração dos Oitenta, questionou o regime cubano de maneira abrangente, mesmo desde posições não antagônicas, e provocou necessariamente um profundo desapontamento no "Sistema" - com um perfil paternalista e repressor das liberdades

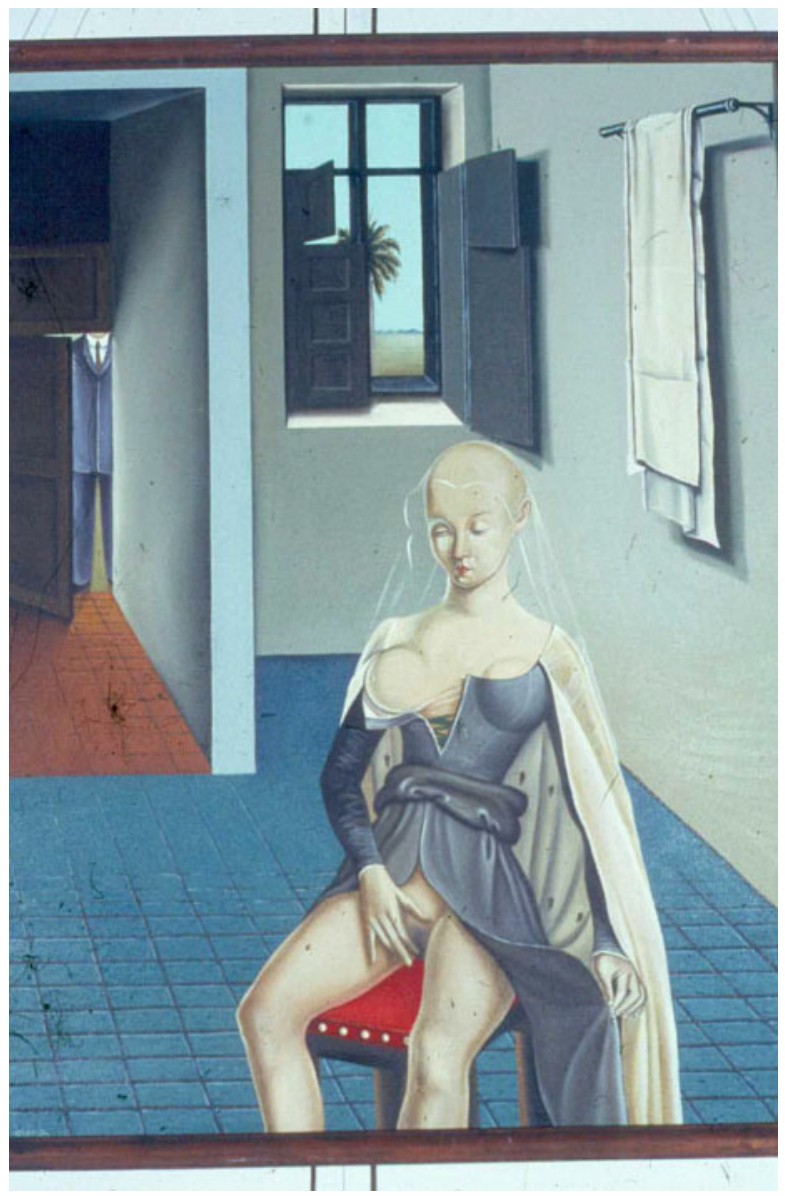

Figura 2 - Néstor Arenas. Masturbação Ilegal. Óleo/tela, Ca. $1988-89$ 
artísticas de expressão - que reagiu ante o reclamo de mudanças, implantando mecanismos defensivos em um primeiro estágio e posteriormente, a partir da aplicação de uma política dirigida ao desapontamento, à censura, o silenciamento e o descaso dos projetos artísticos que provocaram o paulatino desmembramento e o êxodo, da maior parte de seus integrantes; em uma espécie de "Síndrome de Urano" em que o estado paternal, tentou negar ou devorar os filhotes gerados na sua própria dinâmica interna. Porém, nosso estudo também mostrou como a ressonância poética da "Generación de los Ochenta", foi logo continuada pelos jovens integrantes da subseqüente promoção artística.

Em soma, a "Generación de los Ochenta" não teve uma definição de movimento revolucionário e sim de movimento evolucionista. Suas reivindicações nunca se propuseram a mudança radical do sistema, e sim a modificação e a evolução do "status quo" do indivíduo e de sua valoração como componente autônomo dentro do coletivo, desde as posições de preservar as conquistas mais importantes do mesmo como totalidade - apesar de que as reivindicações e as atitudes adotadas, apontaram ao exercício do direito à liberdade de expressão artística, à abertura do exercício do direito na multiplicidade de escolhas políticas e sociais - e à busca de soluções que tomassem em conta as camadas nascidas e educadas dentro do sistema, como integrantes das vozes no consenso da totalidade.

POSSÍVEIS REENCONTROS. OS CAMINHOS DO RETORNO.

Uma das maiores interrogações do século que recém começou é a definição do possível destino da llha de Cuba, após a morte ou a declarada incapacidade física de Fidel Castro. A concentração do poder real nas mãos da figura paternalista, chave do fenômeno cubano e a falta de opções de figuras alternativas, de parecido carisma e lucidez para a substituição do poder, que provocou a designação de Raúl Castro, irmão mais novo de Fidel como o fatual herdeiro do "trono", não constitui obviamente a solução mágica de continuidade para o fenômeno de exceção que representa o caso cubano.

Além de qualquer especulação nas movediças areias da política, é preciso lembrar como o acontecimento cultural na Ilha, esteve sempre relacionado com os meandros do poder real, já fosse como contraponto opositor, ou como plataforma de apoio.

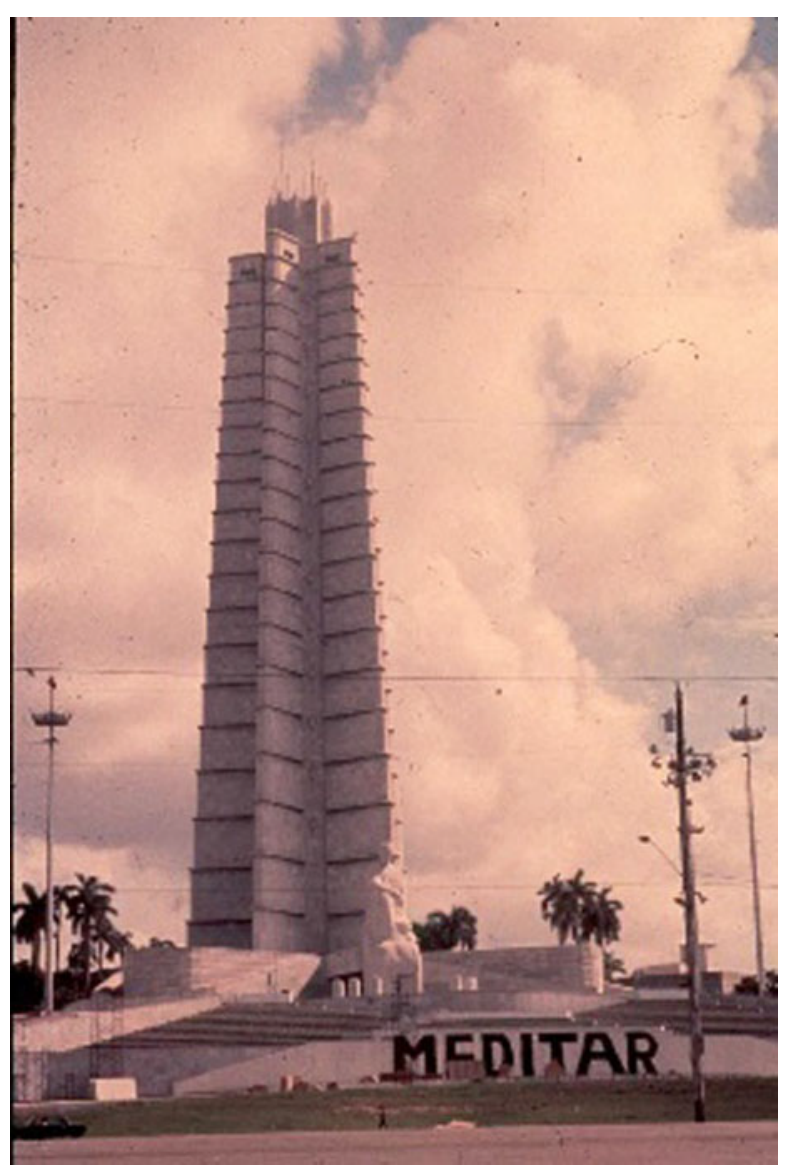

Figura 3 - Ação plástica em Havana, na Plaza da Revolução pelos festejos do aniversário do nascimento de Che Guevara, julho de 1988 
O certo é que a vanguarda artística como equivalente de transgressão, sempre manteve em Cuba um sentido de continuidade, representado na vanguarda dos anos Vinte ou Geração de Avance; continuado na Geração dos anos Sessenta, e por último na Geração que centra a nossa atual reflexão.

Os integrantes daquela primeira avançada que consolidou a "Generación de los Ochenta", na atualidade dispersa pelos cantos do planeta, ainda insistem em manter um forte elo criativo com os artistas da Ilha.

O diálogo continua em uma ponte que ultrapassa as incompatibilidades políticas, ou as divergências estéticas, em uma busca de sentido que se sustenta firmemente na base da identidade nacional.

A arte cubana continua na trilha de luta acesa pelas primeiras vanguardas, e segue o mesmo destino do seu povo. Nestes momentos de incerteza ante os novos rumos, parece que hoje, a diferença do distante mês de julho de 1988, em ocasião da celebração do ani-versário do nascimento de Ernesto - Che - Guevara, o apelo a "Meditar", feito pelos jovens às autoridades na ação coletiva de artistas plásticos e estudantes das Escolas de Arte da capital, nos muros do pódio da Praça da Revolução; deve completar seu ciclo de trans-formações internas, para erigir-se no mais urgente e imediato empenho coletivo: "Evoluir", "Transformar", "Melhorar".

\section{Bibliografia:}

AA.VV. Made in Havana. Contemporary Art from Cuba. Catálogo exposição coletiva, Mel-bourne, Art Gallery of New South Wales; Museum of
Contemporary Art, Brisbane; Australian Centre for Contemporary Art, Melbourne,1988.

AA.VV. Raíces en acción. Nuevos artistas de cuba. Catálogo exposição coletiva, México D.F., Museo de Arte Carrillo Gil,1988.

AA.VV. El Objeto Esculturado. Catálogo exposição coletiva, Ciudad de La Habana, Centro de Desarrollo de las Artes Visuales, mayo-julio de 1990.

AA.VV. Ensayo sobre América, Juan Francisco Elso. Catálogo exposição individual, La Habana, Casa de la Cultura de Plaza, marzo 1996.

AA.VV. La Generación de la Esperanza Cierta. Exposición de jóvenes artistas plásticos cubanos. Catálogo exposição coletiva, Sinaloa, Universidad Autónoma de Sinaloa. Salón de la Plástica Mexicana, Ediciones Renacimiento, A.C., mayo de 1981.

AA.VV. Trajectoire Cubaine. José Bedia, Humberto Castro, Moisés Finalé, José Franco. Corbeil-Essonnes, Commune d'Orvieto; Museo Cívico di Gibellina; Centre d'Art Contem-porain CAC Pablo Neruda de Corbeil-Essonnes, avril de1989.

AA.VV. Cuba: La isla posible... Barcelona, Centre de Cultura Contemporánia de Barcelo-na y Ediciones Destino,1995.

AA.VV. Homenaje a Hans Haacke. Ciudad de La Habana, julio de 1989.

BENÍTEZ ROJO, Antonio. La isla que se repite. Barcelona: Editorial Casiopea,1998.

BRUGUeRA, Ana. Ana Mendieta. Tania Bruguera. Catálogo exposição individual, La Habana, Centro de Desarrollo de las Artes Visuales, enero 1992.

CABALLERO, Rufo. América Clásica: Un paisaje con otro sentido. Ciudad de La Habana: Ediciones Unión, 2000.

CAMNITZER, Luis. New Art of Cuba. Austin: University of Texas Press: Austin, 1994.

DE LA NUEZ, Iván. La balsa perpétua: soledad y conexiones de la cultura cubana. Barce-lona: Editorial Casiopea, 1998.

DE LA TORRIENTE, Loló. Estudio de las Artes Plásticas en Cuba. La Habana: Impresores úcar García, 1954. 
HERNÁNDEZ, Abdel. Elso Padilla: La cultura como técnica de operar. Conferência ditada no evento teórico da Terceira Bienal de Havana, abril de 1990.

HERNÁNDEZ, Abdel. Prédica y praxis de la heraldía. IN: El Caimán Barbudo. Ciudad de La Habana, año 24, n. 271, junio de 1990.

HERRERA YSLA, Nelson. Color de la Bienal. IN: Revolución y Cultura. Ciudad de La Habana, n. 1, 1990.

LÓPEZ RAMOS, Rafael. De un sistema social humanista a un concepto antropológico del arte. IN: Revolución y Cultura. Ciudad de La Habana, n. 7, julio de 1989.

MARTÍ, José. Nossa América. Niterói: Centro de Estudos Martianos / Casa de Las Améri-cas, 1992.

MARTÍ, José. Obras Completas. (32 Vol.) Ciudad de La Habana: Editorial de Ciencias Sociales,1975.

MÉNDEZ, Roberto. Simuladores en trance. IN: Revolución y Cultura. Ciudad de La Haba-na, n. 4, 1990.

MOSQUERA, Gerardo. Arte y Mística en Elso. IN: La Gaceta de Cuba. Ciudad de La Habana, noviembre 1989.

MOSQUERA, Gerardo. Elso en México. IN: Revolución y Cultura. Ciudad de La Habana, n. 1-2, 1991.

MOSQUERA, Gerardo. Exploraciones en la plástica cubana. Ciudad de La Habana: Ed. Letras Cubanas, 1983.

MOSQUERA, Gerardo. Feminismo en Cuba? IN: Revolución y Cultura. Ciudad de La Habana, n. 6, junio de 1989.

MOSQUERA, Gerardo. La última silueta. IN: El Caimán Barbudo. Ciudad de La Habana, febrero 1987.

MOSQUERA, Gerardo. Raíces en Acción.IN: La Gaceta de Cuba. Ciudad de La Habana, mayo 1988.

MOSQUERA, Gerardo. Última conversación con Elso. IN: Revolución y Cultura. Ciudad de La Habana, n. 5, mayo 1989.

NAVARRO, Desidério. Crítica de la crítica, en estos tiempos postmodernos de la postcrítica. IN: La Gaceta de Cuba. Ciudad de La Habana, marzo de 1990.
NAVARRO, Desidério. Un Beuys en fin, cubano. IN: La Gaceta de Cuba. Ciudad de La Habana, julio de 1990.

ORTIZ, Fernando. Entre Cubanos. Psicología Tropical. Ciudad de La Habana: Editorial de Ciencias Sociales, 1987.

PEDROSA MORGADO, Concepción R. Cuba Va: La plural identidad del Presente. IN: Revista Plural, Suplemento Cultural do Jornal Excelsior. Ciudad México, D.F., marzo de 1993.

PEDROSA MORGADO, Concepción R. Encuentros con el Tiempo y su reflejo. IN: Jornal Granma, Sección Culturales. Ciudad de La Habana, Ano 28, n. 266, 22 de dezembro de 1992.

PEDROSA MORGADO, Concepción R. Imago llha: Epifania da "Generación de los Ochenta"cubana. (Mestrado em Ciência da Arte) Universidade Federal Fluminense, 2001.

PEDROSA MORGADO, Concepción R. Juan Marinello, Revista de Avance y el Arte Nuevo en Cuba. Catálogo da exposição do mesmo nome inaugurada na Amostra Colateral da II Bienal, La Habana, Segunda Bienal de La Habana, novembro de 1986.

PEDROSA MORGADO, Concepción R. La plástica cubana frente al Siglo XXI. IN: Jornal Excelsior, Sección Ámbito Tres, (publicado em duas partes). México D.F., 30 de agosto e 23 de agosto de 1990.

PEDROSA MORGADO, Concepción R. La Sedimentación de los símbolos en los años setenta. IN: Jornal Excelsior, Sección Ámbito Tres, (publicado em três partes). México, D.F., 26, 19 e 12 de marzo de 1991.

PEDROSA MORGADO, Concepción R. Los años Ochenta en el arte cubano. IN: Ventana, Artes y Letras, Suplemento cultural do Jornal Listín Diário. Santo Domingo, domingo 26 de maio de 1991.

PEDROSA MORGADO, Concepción R. Plasmación épica de la realidad. IN: Jornal Excelsior, Sección Ámbito Tres, (publicado em duas partes). México D.F., 07 e 05 de fevereiro de 1991.

PORTUONDO, José Antonio. Capítulos de Literatura Cubana. Ciudad de La Habana: Edi-torial Letras Cubanas, 1981.

ROJAS, Rafael. Isla sin fin. Contribución a la crítica del nacionalismo cubano. Miami: Ediciones Universal, 1998. 
SÁNCHEZ, Osvaldo. Bedia, lo mágico de la tierra. IN: Revolución y Cultura. Ciudad de La Habana, n. 10, 1989.

SÁNCHEZ, Osvaldo. La llama de la Parodia. IN: El Caimán Barbudo. Ciudad de La Haba-na, año 21, edición 245, ,abril de 1988.

SCHELER,Max. EL Resentimento y el Juício Moral de los Valores. Buenos Aires: Ed. El siglo del saber, 1912.

SOMOZA, Alexis. La obra no basta. Ensayos y comentarios sobre arte, cultura y sociedad cubana. Valencia, Universidad de Carabobo, 1991.

TORRES LLORCA, Rubén. Lázaro Saavedra. Una mirada retrospectiva. IN: Catálogo ex-posição "Una mirada retrospectiva". Ciudad de La Habana, Centro de Artes Plásticas y Diseño, s/d.

${ }^{1}$ PEDROSA MORGADO, Concepción R. Imago Ilha: Epifania da "Generación de los Ochenta"cubana (Mestrado em Ciência da Arte) Universidade Federal Fluminense, 2001

${ }^{2}$ As citações sob o autor que faremos no percurso do capítulo correspondem à obra recolhida em PORTUONDO, José Antonio. Capítulos de Literatura Cubana. Cidade de Havana, Editorial Letras Cubanas, 1981

${ }^{3}$ PORTUONDO, J.A. op. cit. pp. 22

${ }^{4}$ PORTUONDO, J.A. op. cit. pp. 26

${ }^{5}$ PORTUONDO se remete à citação de um aconteci- mento cultural como as condições que deram origem ao Período Renascentista em comparação com um fato histórico geral como uma revolução ou uma guerra, definido como Acontecimento Catastrófico. PORTUONDO, J.A. op. cit. pp. 26

\begin{abstract}
${ }^{6}$ Relativo à esta necessidade de idealização, cita os exemplos da poesia do inglês Byron e do cubano Espronceda, que reiteraram a imagem do proscrito e do bandoleiro com que os românticos expressaram seu afã literário de liberdade anárquica, e sua rebelião contra as normas sociais do meio burguês. PORTUONDO, J.A. op. cit. pp. 27
\end{abstract}

${ }^{7}$ PORTUONDO, J.A. op. cit. pp. 27-28

${ }^{8}$ SCHELER,Max. EL Resentimento y el Juício Moral de los Valores, Buenos Aires, Ed. El siglo del saber, 1912.

9 PEDROSA MORGADO, Concepción R. Imago Ilha: Epifania da "Generación de los Ochenta"cubana (Mestrado em Ciência da Arte) Universidade Federal Fluminense, 2001. Ver os capítulos referidos ao Período Revolucionário (anos sessenta), Período Pós-Revolucionário (anos setenta) e Os Filhos de Guilherme Tell (anos oitenta).

${ }^{10}$ PEDROSA MORGADO, op.cit.

${ }^{11}$ PEDROSA MORGADO, op.cit.

${ }^{12}$ Em alusão à tomada do Quartel Moncada na cidade de Santiago de Cuba por Fidel Castro, Abel Santamaría, e o resto dos jovens que começaram a luta armada em Cuba.

13 IMAGEM E VIOLÊNCIA. Fórum Internacional de Comunicação Gráfica da SENAC, Centro de Comunicação e Artes, São Paulo, 1994.

14 ALONSO, Ángel. Modo eficaz de apagar la luz, instalação, 1990 (Modo eficaz de desligar a luz), exposição El Objeto Esculturado, 1990

\section{Contato:}

Concepción R. Pedrosa Morgado de Segre cconchyy@yahoo.com

\section{Artigo recebido em Maio de 2011}

